\title{
Application of Civil Engineering in Computer
}

\author{
Zhou Lushui \\ Jiangxi College Of Foreign Studies
}

\begin{abstract}
Since the implementation of China's reform and opening up policy, along with the potential of computer hardware controls the level of technology advancement trend has large capacity, miniaturization direction, and in that the basic conditions of storage technology and image processing, optical communications, interactive network gradually clear pattern in one respect it is a great show to attract broaden the field of computer applications. In civil engineering practice, a computer application conditions are not entirely dependent on CAD software program framework for planning, more importantly, extend the life cycle and meticulous preparation aspects of the project, in conjunction with the visual monitoring and virtual multimedia operating means to achieve accurate design calculations and precise positioning. This article describes computer applications in civil engineering achievements, especially in the current situation and prospects of civil engineering expert system, which is for the promotion of computer technology in civil engineering is important.
\end{abstract}

Keywords: Computer science and technology; computer technology; CAD; Civil engineering

\section{INTRODUCTION}

Since the 1990s, computer technology has been rapid development, and progress of high-capacity data storage, image voice processing and network communications technology is to broaden the applications of the computer. The civil engineering studies often need to create complex mathematical models to deal with large amounts of data and experimental study of repeated, thus providing a broad application platform for computer-aided design and simulation technology. Human - Computer Interaction (HCI) theory and technology is a key current development of computer applications, computer sound synthesis process has the ability to text, graphics information, its image and convenient interaction, greatly improved the man-machine interface, civil engineering research methods has been a breakthrough.

CAD continues to mature technology is compelling. In addition to $\mathrm{CAD}$ engineering drawings outside and have incorporated visual field of animation techniques used to make out, the light changes, surface decoration, size changes, buildings and other environmental effects of using computer simulation. CAD is the development process from the Interactive CAD System to Optinrna1 CAD System, and then Intelligent CAD System, and finally the formation of Interactive Intelligence integrated CAD (III CAD).

On the premise of the development history of computer, this paper points out the status of computer science and technology through the combination and application of modern science and technology and computer science and technology. Through the development of computer science and technology in our country and the world, we can sum up the development and application of computer science and technology, and to clarify the overall development trend of computer science and technology.

\section{COMBINATION AND APPLICATION OF MODERN}

\section{SCIENCE AND TECHNOLOGY WITH COMPUTER SCIENCE}

\section{A. Strengthening being Comprehensive and} Professional

From understanding the objective world to transforming the objective world, the formation of specialized and integrated such a contradiction. On the one hand requires a deep objective world, requires careful division of science and technology, and on the other hand in order to meet national policy and the economy, they must integrate the professional segments, after all, a lot of work alone cannot be solved on the one hand professional. Strengthening integrated and specialized, for this reason, electronic technology permeates national life so as not to 
cause great distress or confusion.

\section{B. To Penetrate Various Aspects like Economy, Social Culture and Commercial Circulation}

Science is absolutely the first productivity, both in the past and now. Computer science and technology in modern society as productive potential, has a pivotal position, with research funds invested more and more, more and more large-scale work, also will increase the difficulty and expense, for the sake of economic and social activities can successfully adapt to the development of science and technology, widely used in electronic technology is imperative.

\section{Circulation of Modern Science and Technology Application in New Products is Shortened}

From the invention of electronic tube in 1904 to the invention of the first computer in 1946, it only takes 42 years. The invention of the transistor from the semiconductor to create a semiconductor computer, only about 10 years. The microelectronics fine processing technology to integrated circuit computer only time less than 2 years. The ultra-fine processing technology to the creation of the fourth generation of computers, can be said to be synchronized breakthrough. "Technological breakthroughs" based technology gradually give way "systems integration" type of science and technology.

\section{APPLICATION OF COMPUTER VIRTUAL SIMULATION IN CIVIL ENGINEERING}

Computer virtual simulation study is to establish and develop the main content structure of the system model and simulation analysis methods. Development of simulation system is an application of computer technology can be used, drawing technical computer-related fields. Key civil engineering researchers are modeling and analysis of structures and components. Modern computer simulation technology to develop simulation technology and computer combine to numerical calculation as a means of existence or contemplated in the system tested. Now, you can render animated simulation dynamic simulation calculations automatically generate a series of functions and the outcome document. Its advantages mainly in the following aspects.

A. In the computer virtual simulation, mathematical models can often resolve civil engineering reality difficult or impossible to achieve, constitutive relation, etc.

For example, there are several concrete constitutive relationships, but also has a variety of failure criterion, and each criterion has a certain scope, while constitutive relation is to fit the experimental data, the theory cannot be derived, so the actual analysis of its when strength and durability is very complicated.

B. Computer virtual simulation can simulate the situation, environmental changes and emergence in design results

For example, using software to build a bridge or building models, various loads applied thereto or change its structure (including size, steel configuration, etc.), and then simulate stress analysis, we can clearly get results so as to perform its mechanical properties a series of evaluation.

\section{APPLICATION OF CAD SYSTEM}

Expert systems are also an attractive area of computer application. It is a simulation expert thinking for problem analysis and solving computer program, mainly by basic parts knowledge base, inference engine, an interpreter and a user interface and other components. A typical project type system is shown in Figure 1. 


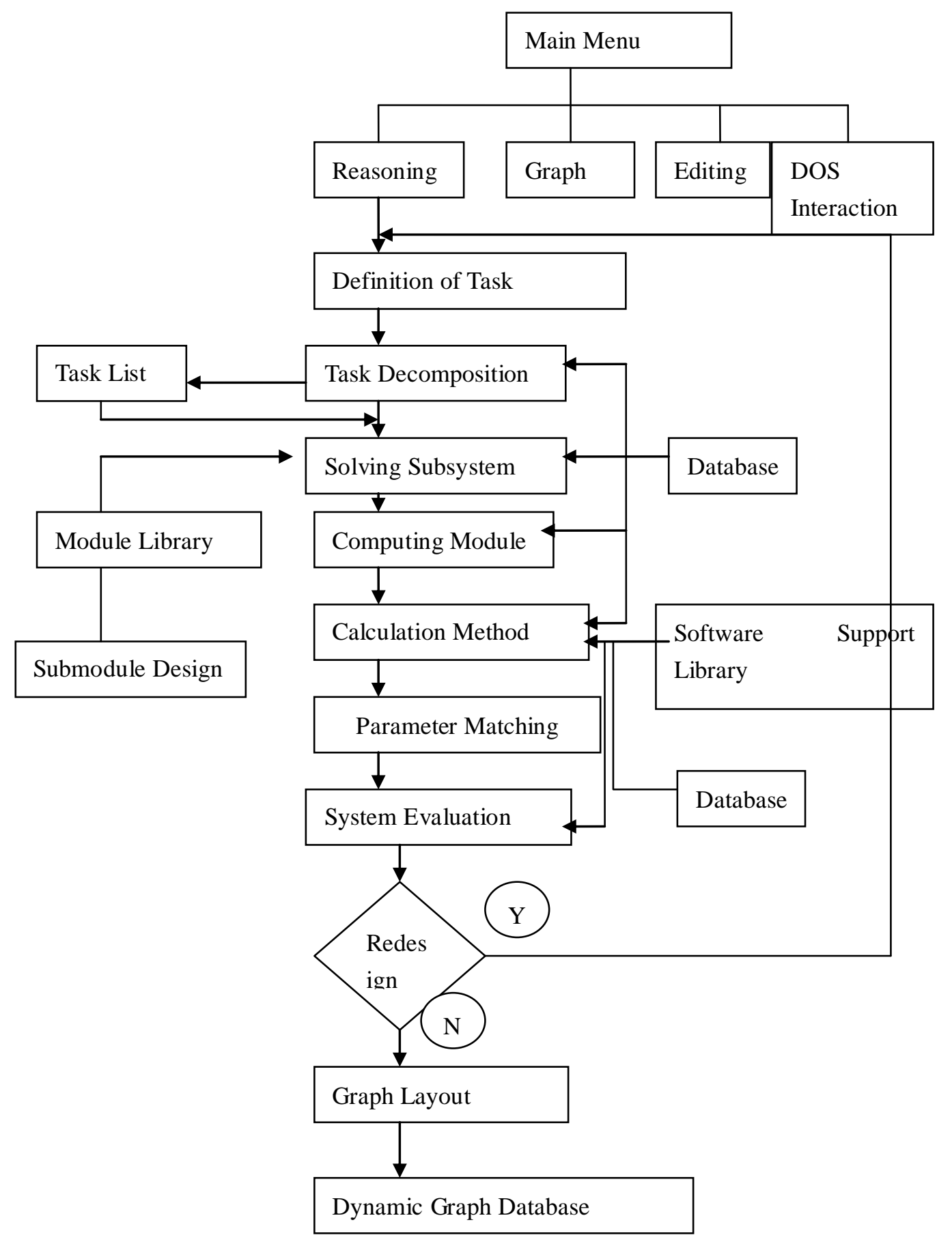

Figure 1. Engineering System Diagram

Knowledge base is a static database used to store knowledge. A good expert system is able to express domain knowledge very well and store it in the knowledge base.

Reasoning machine is a problem solving strategy for expert system. Usually there are positive, negative and mixed reasoning. Positive reasoning and data driven, is based on the existing facts and rules to deduce the conclusion of the reasoning method.

The interpreter is a system used to answer questions from users in the process of reasoning. System in the process of reasoning in the context of the dynamic database records in order to answer the user's questions such as why, how, what and other issues.

The graphics module and the internal force analysis module are unique to the engineering expert system, 
which often lead to the mature finite element and the CAD software package to the system, and realize the full automation and intelligent of the expert system.

\section{CONCLUSION}

The application of computer technology in the field of civil engineering has changed the traditional research methods to a certain extent, which effectively improved the working efficiency of civil engineering projects. We believe that in the future the computer aided design technology and computer simulation technology can get a more extensive development, while combining with multimedia, network technology, collaborative work environment to enter our research and development areas, and thus become an effective means of engineering design, construction and scientific research. Computer in civil engineering is widely used in the long-term development of the relevant enterprises to provide specific protection, while promoting the overall industry's progress. In the computer information chart, the project construction plan index basis one by one to reveal. In addition, the computer technology is still in the engineering software development pattern to accelerate the pace of development, the scientific transformation of the overall civil engineering to adapt to dynamic factors, improve the overall quality level of the engineering industry, and realize the economic value of the reasonable optimization, and finally meet the long-term development of enterprises.

\section{REFERENCES}

[1]Davis F D, Bagozzi R P, Warshaw P R. User Acceptance of Computer Technology: A Comparison of Two Theoretical Models[J]. Management Science, 1989, 35(8):982-1003.

[2]Wears R L, Berg M. Computer Technology and Clinical Work: Still Waiting for Godot[J]. Jama, 2005, 293(10):1261-1263.

[3]Venkatesh V, Speier C. Computer Technology Training in the Workplace: A Longitudinal Investigation of the Effect of Mood[J]. Organizational Behavior \& Human Decision Processes, 1999, 79(1): $1-28$.

[4]Venkatesh V, Speier C. Computer Technology Training in the Workplace: A Longitudinal Investigation of the Effect of Mood[J]. Organizational Behavior \& Human Decision Processes, 1999, 79(1): 1-28.

[5]Friedman B. Human values and the design of computer technology[M]// Center for the Study of Language and Information, 1997.

[6]Collins A. The Role of Computer Technology in Restructuring Schools.[J]. Phi Delta Kappan, 1991, 73(1):28-36.

[7]Hennessy, John L., and N. P. Jouppi. "Computer Technology and Architecture: An Evolving Interaction." Computer 24.9(1991):18-29.

[8] Lehmer, D. H. "Computer technology applied to the theory of numbers." Studies in Number Theory 1969.

[9]Milbrath Y C L, Kinzie M B. Computer Technology Training for Prospective Teachers: Computer Attitudes and Perceived Self-Efficacy.[J]. Journal of Technology \& Teacher Education, 2000, 8(4).Milbrath Y C L, Kinzie M B. Computer Technology Training for Prospective Teachers: Computer Attitudes and Perceived Self-Efficacy.[J]. Journal of Technology \& Teacher Education, 2000, 8(4).

[10]Chapelle C, Douglas D. Assessing language through computer technology[M]// Cambridge University Press, 2006.

[11]Czaja, S. J. "Computer technology and the older adult." Handbook of Human-Computer Interaction (1997):791-824.

[12]Salomon G. Cognitive Effects with and of Computer Technology.[J]. Communication Research, 1990, 17:26-44. 